\title{
Produtividade e valor nutritivo da Brachiaria brizantha cv. Marandu em um sistema silvipastoril
}

\author{
[Productivity and nutritional value of Brachiaria brizantha $c v$. Marandu in a silvopastoral system] \\ L.F. Sousa ${ }^{1}$, R.M. Maurício ${ }^{2 *}$, L.C. Gonçalves ${ }^{3}$, E.O.S. Saliba ${ }^{3}$, G.R. Moreira ${ }^{1}$ \\ ${ }^{1}$ Aluno de pós-graduação - EV-UFMG - Belo Horizonte, MG \\ ${ }^{2}$ Fundação Ezequiel Dias \\ Rua Conde Pereira Carneiro, 82 \\ 30510-010 - Belo Horizonte, MG \\ ${ }^{3}$ Escola de Veterinária - UFMG - Belo Horizonte, MG
}

\begin{abstract}
RESUMO
O experimento foi realizado em sistema silvipastoril ( $\mathrm{Ssp}$ ) localizado no bioma de Cerrado, no município de Lagoa Santa, Minas Gerais, no ano agrícola de 2004-2005. Avaliou-se a influência do Ssp composto pela arbórea bolsa-de-pastor (Zeyheria tuberculosa) sobre os parâmetros produção, atributos morfogênicos, composição bromatológica e valor nutritivo da gramínea Brachiaria brizantha cv. Marandu, e os efeitos sobre as condições microclimáticas. O delineamento experimental foi em blocos ao acaso, com cinco blocos (épocas de corte), dois tratamentos (T1 - B. brizantha $\mathrm{cv}$. Marandu sombreada com a $Z$. tuberculosa e T2 - B. brizantha cv. Marandu, a pleno sol) e três repetições (parcelas). O sombreamento proporcionado pela $Z$. tuberculosa, apesar de reduzir a produção de matéria seca (MS) da gramínea, favoreceu o aumento do teor de proteina bruta (PB) e não alterou a produção de $\mathrm{PB} / \mathrm{ha}$ e nem afetou a concentração de FDN. Os teores de FDA foram mais altos que os encontrados a pleno sol, o que provavelmente resultou em menor degradabilidade in vitro da MS e da matéria orgânica, não alterando a degradabilidade efetiva.
\end{abstract}

Palavras-chave: nutrição animal, sistema silvipastoril, sombreamento

\begin{abstract}
The experiment was carried out in a Silvopastoral system (Sps) located in Brazilian Savannah, Lagoa Santa county, Minas Gerais State, during the agricultural year of 2004-2005. It was studied the influence of Sps formed by "Bolsa de Pastor" (Zeyheria tuberculosa) on the production, morphogenic attributes, bromatological composition and nutritional value of the graminaceous Brachiaria brizantha cv. Marandu as well as on the microclimatic aspects. The Sps was established in 1982, in a red-yellow latossol by the natural regeneration process. The experiment was based on a randomized block design, with 5 blocks (cutting times), 2 treatments (T1 - B. brizantha $c v$. Marandu shaded by Z. tuberculosa and T2 - B. brizantha $c v$. Marandu at open sky and three repetitions (plots). Although the DM production of the graminaceous in the Sps with Z. tuberculosa has reduced the level of crude protein $(C P)$ has increased and the production of CP per ha and the Sps NDF concentration have remained unchanged. However, the levels of $A D F$ were higher in the shaded area, which probably resulted in lower in vitro DM and organic matter degradability, but similar effective DM degradability.
\end{abstract}

Keywords: animal nutrition, silvopastoral system, shading

Recebido em 27 de março de 2006

Aceito em 19 de março de 2007

*Autor para correspondência (corresponding author)

E-mail: rogério.mauricio@funed.mg.gov.br 


\section{INTRODUÇÃO}

Os sistemas agroflorestais (SAF), em suas diferentes modalidades, sistemas agrossilviculturais, agrossilvipastoris e silvipastoris (Macedo et al., 2000), são opções agroecológicas que incluem em seus conceitos referências aos principais componentes da sustentabilidade, ou seja, o econômico, o social e o ambiental.

Os sistemas silvipastoris ( $\mathrm{Ssp}$ ) são associações de espécies florestais com plantas forrageiras herbáceas ou rasteiras e animais herbívoros que buscam a sustentabilidade de pastagens naturais e cultivadas, além de obter múltiplos produtos vegetais e animais como madeira, carne e leite (Carvalho et al., 1995).

Em virtude da procura por opções de produção sustentáveis por parte da sociedade mundial, as diferentes tecnologias agroecológicas e em especial os Ssp têm apresentado avanços no que diz respeito à sua adoção. No entanto, segundo Carvalho et al. (2002), a sua implantação está ligada à divulgação das vantagens dos Ssp e também à necessidade de pesquisas sobre alguns aspectos importantes como a adaptação e o desempenho das espécies às diferentes condições de clima e solo e os procedimentos para implantação dos diversos tipos de Ssp.

A região dos cerrados brasileiros ocupa $23 \%$ do território nacional, estendendo-se do sul da Floresta Amazônica até os estados de São Paulo e Paraná. Os cerrados de Minas Gerais possuem alta concentração de pequenas propriedades, bacias hidrográficas desordenadas, alta densidade demográfica em seus municípios, e o êxodo rural nessas áreas é grande devido à crescente mecanização (IBGE, 2005). Tais aspectos são pré-requisitos expressivos para a dispersão e a adoção de Ssp.

Assim, há necessidade de escolher forrageiras que possam ser utilizadas sob condições de luminosidade reduzida (Castro et al., 1999). As gramíneas do gênero Brachiaria são largamente utilizadas em pastagens na América Tropical e, segundo Carvalho et al. (1997), podem ser utilizadas em condições de sombreamento natural.
As árvores, além de serem cada vez mais necessárias para melhorar a produção, a qualidade e a sustentabilidade das pastagens, contribuem para o conforto dos animais, pela provisão de sombra, atenuam as temperaturas extremas e diminuem o impacto da chuva e do vento e servem até de abrigo (Carvalho, 1998).

A bolsa-de-pastor (Zeyheria tuberculosa Vell. Bur. - família: Bignoniaceae) é uma árvore nativa pioneira, de madeira leve, resistente e flexível típica do bioma cerrado. Possui características como crescimento rápido $\mathrm{e}$ facilidade de multiplicação, o que a torna interessante para reflorestamentos heterogêneos destinados à recuperação de áreas degradadas (Lorenzi, 1992), e apresenta arquitetura de copa favorável à sua utilização em Ssp.

Este trabalho teve o objetivo de avaliar a produtividade e o valor nutritivo da gramínea Brachiaria brizantha cv. Marandu, sob a influência da arbórea bolsa-de-pastor (Zeyheria tuberculosa Vell. Bur.), e estudar sua composição bromatológica e digestibilidade in vitro da matéria seca (MS), além de caracterizar as condições micro-climáticas desse Ssp durante a estação chuvosa.

\section{MATERIAL E MÉTODOS}

O Ssp utilizado para este experimento foi desenvolvido em 1982, em solos classificados como latossolos vermelho-amarelo por meio de regeneração natural, utilizando-se da técnica de roçada seletiva. A gramínea Brachiaria brizantha $\mathrm{cv}$. Marandu foi implantada utilizandose tração animal para esparramar o fosfato natural e o calcário, e as sementes foram esparramadas manualmente entre as árvores (Viana et al., 2002).

O experimento foi realizado durante a estação chuvosa do ano agrícola 2004-2005, em um Ssp localizado na fazenda Grota Funda, nas seguintes coordenadas geográficas: $19^{\circ}, 35^{\prime}, 36^{\prime \prime}$ sul, $43^{\circ}$, 51', 56" oeste; altitude $747 \mathrm{~m}$, correspondente a uma área de bioma do cerrado do município de Lagoa Santa, no estado de Minas Gerais (Viana et al., 2002).

O experimento foi composto por um sistema arborizado $(\mathrm{T} 1=$ Brachiaria brizantha cv. Marandu sombreada com Z. tuberculosa,160 
árvores por hectare) e seu respectivo controle $(\mathrm{T} 2=$ monocultura de Brachiaria brizantha $\mathrm{cv}$. Marandu, a pleno sol).

O delineamento estatístico utilizado foi o de blocos inteiramente ao acaso com cinco blocos (épocas de corte - dez., jan., fev., mar. e abr.), dois tratamentos (T1 e T2) e três repetições (cercados).

Foram delimitadas três áreas para cada tratamento, sendo estas as repetições dos tratamentos, perfazendo seis áreas. As áreas correspondentes às repetições dos tratamentos foram de 4 x $4 \mathrm{~m}\left(16 \mathrm{~m}^{2}\right)$, localizadas mediante sorteio e cercadas para que não houvesse interferência de animais que estavam em pastejo. Na comparação de médias, usou-se o teste Tukey a $5 \%$ de probabilidade. Equações de regressão para os dados climáticos e produtivos também foram estabelecidas.

Após o corte de uniformização a $30 \mathrm{~cm}$ e período de descanso de 30 dias para que a planta atingisse $60-80 \mathrm{~cm}$ de altura, as amostras foram colhidas a $30 \mathrm{~cm}$ do solo, utilizando-se o método do quadrado, simulando, assim, o manejo correto da Brachiaria brizantha cv. Marandu (Silva, 1995).

As precipitações pluviométricas e umidades relativas mensais foram obtidas na Estação Meteorológica do Aeroporto de Confins, sendo esta a mais próxima à área experimental.

Com o objetivo de obter dados relacionados ao grau de sombreamento, mensurou-se a radiação fotossinteticamente ativa (RFA), sendo esta a energia luminosa disponível para realização de fotossíntese, obtidas com quantômetro digital ${ }^{1}$ nos dois tratamentos. As medidas foram feitas no dia 2 de abril de 2004, e a metodologia utilizada foi a recomendada por MacCree (1981). Foram obtidas semanalmente temperaturas máximas e mínimas utilizando termômetros de álcool.

As amostras de forragem colhidas foram utilizadas para estimar a relação vivo:morto (V:M) e a relação limbo:haste $(\mathrm{L}: \mathrm{H})$, e realizar as análises bromatológicas $\mathrm{e}$ in vitro. Os procedimentos laboratoriais foram os de rotina para experimentos dessa natureza. A metodologia usada foi repetida em cada época de colheita.

${ }^{1}$ LI-1400 DataLogger, Lincoln - EUA.
Foram realizadas as seguintes análises bromatológicas: matéria seca (MS), matéria mineral (MM) (Compêndio..., 1998), proteína bruta (PB) pela metodologia de Kjeldahl (Official..., 1980), fibra em detergente neutro (FDN), fibra em detergente ácido (FDA), com o aparelho "Ankon" pelo método seqüencial (Van Soest et al., 1991).

Foram feitos ensaios de degradabilidade e descrição de cinética de fermentação por meio da técnica in vitro semi-automática de produção de gases (Maurício et al., 1999). O modelo de France et al. (1993) foi utilizado para estimar os parâmetros referentes à cinética de produção de gases sendo estes: a produção de gases cumulativa (ml) $\mathrm{y}$, o tempo de incubação $\mathrm{t}$ (horas), o total de gases (ml) A, o tempo de colonização $\mathrm{T}$ (horas) e a taxa de degradação fracional $\left(\mathrm{h}^{-1}\right) \mu$. A taxa de passagem para $\mathrm{o}$ cálculo de degradabilidade efetiva foi 0,02 .

\section{RESULTADOS E DISCUSSÃO}

As equações de regressão da Tab. 1 relacionam os dados climáticos com os produtivos, descrevendo a dependência dos tratamentos aos fatores climáticos. As equações crescentes indicam que quanto maiores são os valores de precipitação e umidade relativa maiores são as produções de matéria seca e proteína bruta. Além disso, pode-se observar que os coeficientes de determinação $\left(\mathrm{R}^{2}\right)$ das equações de ajuste linear para os parâmetros climáticos e produtivos para a área sombreada (T1) possuem valores menores em relação à área a pleno sol (T2). Tal constatação confirma a de Nunes (1985), que afirma que o desempenho da Brachiaria brizantha cv. Marandu está relacionado à precipitação e à umidade relativa do local onde é cultivada. Isso indica que em Ssp as produções de matéria seca de forragem e de proteína bruta por unidade de área podem depender menos das condições de precipitação e umidade relativa. Esses dados estão de acordo com Anderson et al. (1988), que verificaram que o solo sob a copa de árvores apresenta maior teor de umidade e que em Ssp ocorre diminuição da demanda evapotranspirativa das plantas herbáceas e rasteiras do sub-bosque, em face das condições climáticas amenas e da menor velocidade dos ventos. 
Tabela 1. Equações e coeficientes de determinação das regressões para os parâmetros climáticos e produtivos dos sistemas com Zeyheria tuberculosa (T1) e controle (T2)

\begin{tabular}{cccc}
\multirow{2}{*}{ Tratamento } & \multicolumn{3}{c}{ Precipitação $(\mathrm{mm})$} \\
\cline { 2 - 4 } & Equação & $\mathrm{y}=0,003 \mathrm{x}+0,52$ & $\mathrm{~PB}(\mathrm{~kg} / \mathrm{ha})^{*}$ \\
\hline \multirow{2}{*}{$\mathrm{T} 1$} & $\mathrm{R}^{2}$ & 0,24 & $\mathrm{y}=0,154 \mathrm{x}+80,23$ \\
& Equação & $\mathrm{y}=0,003 \mathrm{x}+0,87$ & 0,08 \\
$\mathrm{~T} 2$ & $\mathrm{R}^{2}$ & 0,80 & $\mathrm{y}=0,143 \mathrm{x}+81,66$ \\
& \multicolumn{3}{c}{0,42} \\
\hline \multirow{2}{*}{ Tratamento } & Equação & $\mathrm{yS}(\text { ton } / \mathrm{ha})^{*}$ & $\mathrm{~PB}(\mathrm{~kg} / \mathrm{ha})^{*}$ \\
\cline { 2 - 4 } & $\mathrm{R}^{2}$ & $0,038 \mathrm{x}-2,15$ & $\mathrm{y}=1,386 \mathrm{x}-1,88$ \\
$\mathrm{n}$ T1 & Equação & $\mathrm{y}=0,049 \mathrm{x}-2,58$ & 0,03 \\
& $\mathrm{R}^{2}$ & 0,80 & $\mathrm{y}=2,132 \mathrm{x}-68,03$ \\
$\mathrm{~T} 2$ & & & 0,41 \\
\hline
\end{tabular}

${ }^{\star}$ Média por corte.

$\mathrm{Na}$ Tab. 2 apresenta-se a radiação fotossinteticamente ativa (RFA) dos sistemas. O nível de sombreamento obtido está em torno de $77 \%$, muito alto para Brachiaria brizantha $\mathrm{cv}$.
Marandu segundo Castro et al. (1999), que recomendam sombreamento não superior a $60 \%$ para essa espécie forrageira.

Tabela 2. Dados de radiação fotossinteticamente ativa (RFA) dos sistemas com Zeyheria tuberculosa (T1) e controle (T2)

\begin{tabular}{|c|c|c|c|c|c|c|c|c|c|c|c|c|c|}
\hline \multirow{3}{*}{ Tratamento } & \multicolumn{13}{|c|}{ Horas } \\
\hline & 6 & 7 & 8 & 9 & 10 & 11 & 12 & 13 & 14 & 15 & 16 & 17 & Média \\
\hline & \multicolumn{13}{|c|}{ RFA $\left(\mu \mathrm{mol}\right.$ de Fóton. $\left.\mathrm{s}^{-1} \cdot \mathrm{m}^{-2}\right)$} \\
\hline $\mathrm{T} 1$ & 17 & 51 & 84 & 177 & - & 649 & 658 & 457 & 604 & 742 & 155 & 28 & 329 \\
\hline $\mathrm{T} 2$ & 98 & 542 & 868 & 1530 & - & 2282 & 2253 & 1891 & 1680 & 1200 & 820 & 301 & 1224 \\
\hline Sombreamento ${ }^{1}$ & 83 & 90 & 90 & 88 & - & 72 & 71 & 76 & 64 & 38 & 81 & 91 & 77 \\
\hline
\end{tabular}

Os dados das 10 horas foram perdidos pelo fato de haver nuvens nesse horário, o que poderia confundir a interpretação.

${ }^{1}$ (RFA do T2 - RFA do T1) x 100 / RFA do T2.

No tratamento que incluiu árvores, verificou-se que o sombreamento proporcionou RFA insuficiente para atingir o mínimo $(800 \mu \mathrm{mol}$ de Fóton. $\mathrm{s}^{-1} \cdot \mathrm{m}^{-2}$ ) necessário para $\mathrm{o}$ bom desenvolvimento da gramínea. Isso pode ser um indicativo de que existe a necessidade de realizar a poda da copa ou o corte de árvores com o intuito de aumentar a RFA disponível para a forrageira (Fig. 1). Entretanto, como a medida foi feita no mês de abril, mês de menor RFA, radiações maiores em meses como janeiro e fevereiro poderiam ter alcançado o mínimo desejado.
As temperaturas do ar máximas sob a copa das árvores são mais baixas $\left(4,8^{\circ} \mathrm{C}\right.$ em média) que as obtidas a pleno sol (Tab. 3). Pezo e Ibrahim (1998) relataram que a temperatura do ar sob a copa das árvores em pastagens pode ser de 2 a $3^{\circ} \mathrm{C}$, mais baixa que a observada a pleno sol. A redução da temperatura do ar máxima é um aspecto benéfico, pois ela influencia mecanismos reguladores energéticos, térmicos e hormonais, que são capazes de afetar o crescimento e a reprodução, e alterar a resistência dos animais domésticos às doenças (Ferreira e Cardoso, 1993). 


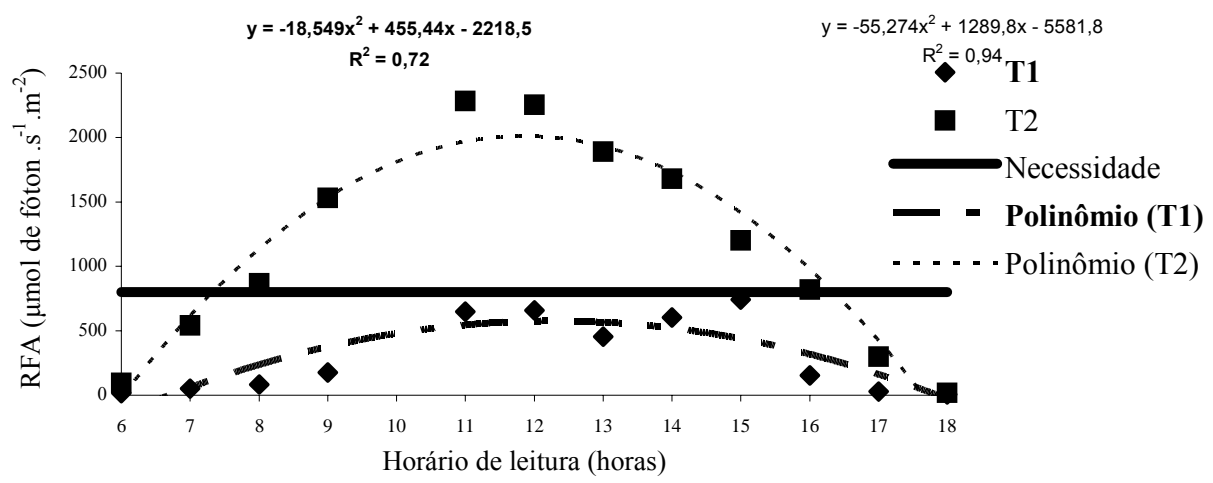

Figura 1. Radiação fotossinteticamente ativa (RFA) dos sistemas com Zeyheria tuberculosa (T1) e controle (T2).

Tabela 3. Temperaturas do ar $\left({ }^{\circ} \mathrm{C}\right)$ nos sistemas com Zeyheria tuberculosa (T1) e controle (T2) segundo mês de coleta

\begin{tabular}{|c|c|c|c|c|c|c|c|}
\hline \multirow{2}{*}{ Tratamento } & \multicolumn{7}{|c|}{ Coleta } \\
\hline & & Dezembro & Janeiro & Fevereiro & Março & Abril & Média \\
\hline \multirow{2}{*}{$\mathrm{T} 1$} & Máxima & 29,0 & 35,8 & 37,0 & 35,0 & 34,0 & 34,2 \\
\hline & Mínima & 19,0 & 19,5 & 18,0 & 18,7 & 16,7 & 18,4 \\
\hline \multirow{2}{*}{$\mathrm{T} 2$} & Máxima & 37,5 & 38,8 & 40,3 & 40,3 & 38,3 & 39,0 \\
\hline & Mínima & 19,0 & 18,5 & 16,5 & 18,0 & 18,0 & 18,0 \\
\hline
\end{tabular}

Townsend et al. (2000), ao estudarem o sombreamento de seringueira (Hevea brasiliensis), árvore com arquitetura semelhante à Z. tuberculosa, em pastagem de Brachiaria brizantha cv. Marandu, concluíram que a sombra dessa espécie propiciou condições térmicas adequadas ao manejo de bovinos de raças européias. Para as raças zebuínas, seu efeito foi mais marcante durante a estação da seca.

As condições ambientais prevalecentes no subbosque da $Z$. tuberculosa concorreram para reduzir $(\mathrm{P}<0,05)$ a produção de matéria seca ton/ha (média de cinco cortes) da forrageira estudada (Tab. 4). Este resultado foi semelhante aos encontrados por Carvalho et al. (1997) e Castro et al. (1999). Os primeiros trabalharam com sombreamento natural sob a copa de angicovermelho (Anadenanthera macrocarpa), e os segundos, com sombreamento artificial progressivo 30 e $60 \%$, ou seja, independente do tipo de sombreamento, houve redução da produtividade da B. brizantha.

Tabela 4. Produção de matéria seca (MS), produção de proteína bruta (PB), teores de MS, PB, fibra em detergente neutro (FDN), fibra em detergente ácido (FDA) e matéria mineral (MM) dos sistemas com Zeyheria tuberculosa (T1) e controle (T2)

\begin{tabular}{cccccccc}
\hline Tratamento & MS (ton/ha $)^{1}$ & $\begin{array}{c}\text { PB } \\
(\mathrm{kg} / \mathrm{ha})^{1}\end{array}$ & $\begin{array}{c}\text { MS } \\
(\%)\end{array}$ & $\begin{array}{c}\text { PB* }^{*} \\
(\%)\end{array}$ & $\begin{array}{c}\text { FDN* } \\
(\%)\end{array}$ & $\begin{array}{c}\text { FDA* }^{*} \\
(\%)\end{array}$ & $\begin{array}{c}\text { MM}^{*} \\
(\%)\end{array}$ \\
\hline T1 & $1,2 \mathrm{~b}$ & $118,7 \mathrm{a}$ & $22,1 \mathrm{~b}$ & $9,7 \mathrm{a}$ & $67,7 \mathrm{a}$ & $34,2 \mathrm{a}$ & $8,1 \mathrm{a}$ \\
$\mathrm{T} 2$ & $1,7 \mathrm{a}$ & $117,5 \mathrm{a}$ & $26,6 \mathrm{a}$ & $6,9 \mathrm{~b}$ & $68,0 \mathrm{a}$ & $32,1 \mathrm{~b}$ & $7,9 \mathrm{a}$ \\
\hline DMS & 0,2 & 22,2 & 1,2 & 0,6 & 1,0 & 1,1 & 0,4 \\
CV (\%) & 20,2 & 24,0 & 6,4 & 9,0 & 1,9 & 4,5 & 6,5 \\
\hline
\end{tabular}

Valores seguidos por letras distintas na coluna diferem entre si pelo teste Tukey $(\mathrm{P}<0,05)$.

1- Média por corte. $\mathrm{DMS}=$ diferença mínima significativa pelo teste Tukey $(\mathrm{P}<0,05), \mathrm{CV}=$ coeficiente de variação.

* Percentual da base seca. 
Com relação à produção total de $\mathrm{PB}$, não houve diferença $(\mathrm{P}>0,05)$ entre os tratamentos (Tab. 4). Carvalho et al. (1997), ao trabalharem com seis gramíneas tropicais cultivadas em sub-bosque de angico-vermelho, verificaram que a produção de PB da $B$. brizantha cv. Marandu foi $47 \%$ mais alta quando esta está sombreada.

O sombreamento reduziu significativamente o teor de MS da forragem estudada, porém, segundo Carvalho et al. (1995), que trabalharam com cinco gramíneas forrageiras tropicais sob a copa de angico-vermelho ( $A$. macrocarpa), a diminuição da MS está ligada a maiores proporções de folhas verdes dessas forragens nas áreas sombreadas, o que representa uma vantagem do ponto de vista do pastejo, uma vez que as folhas geralmente têm melhor valor nutritivo que os caules.

O teor de PB na B. brizantha cv Marandu nos sub-bosques de Z. tuberculosa foi $29 \%$ maior que no seu controle. Tendência similar foi observada por Carvalho et al. (1995), que verificaram que as gramíneas sombreadas apresentaram maior concentração de $\mathrm{N}$ que as gramíneas plantadas a pleno sol.

O teor de FDN da B. brizantha sob o efeito do sombreamento não variou na área sombreada com $Z$. tuberculosa $(\mathrm{P}>0,05)$, quando comparado ao teor da área controle. Entretanto, os teores de FDA foram afetados pelo sombreamento $(\mathrm{P}<0,05)$, isto é, nas áreas sombreadas esses teores foram mais altos. Este resultado deve-se provavelmente ao estiolamento da planta, comprovado pela maior altura do relvado (AMR) nas áreas sombreadas. Estes resultados são semelhantes aos obtidos por Castro et al. (1999) que avaliaram $B$. brizantha cv. Marandu em condições de sombreamento artificial, onde a AMR foi maior com sombreamento de 30 e $60 \%$ que em áreas a pleno sol.

Quanto aos teores de matéria mineral das áreas sombreadas e das áreas a pleno sol (Tab. 4), não foi verificada diferença entre os tratamentos $(\mathrm{P}>0,05)$.

Foram verificadas diferenças $(\mathrm{P}<0,05)$ para $\mathrm{o}$ parâmetro relação vivo:morto, ou seja, houve maior quantidade de material vivo na área sombreada, o que indica que a $Z$. tuberculosa propiciou menor taxa de senescência da forrageira. Esse fato pode ser explicado pelo efeito do sombreamento (Tab. 5) sobre as características morfogênicas como o número de dias de plena atividade da folha, o qual é altamente correlacionado com a relação V:M (Lemaire e Agnusdei, 2000). A mudança no ambiente luminoso, como no caso de sombreamento, pode estimular a atividade das gemas e afetar a formação de novas folhas e perfilhos, além de aumentar a taxa de manutenção de tecido semi-senescentes (Frank e Hofman, 1994). Nutricionalmente, a relação vivo:morto influencia o consumo voluntário de animais no pasto, principalmente quando não há escassez de forragens (Forbes, 1998).

Tabela 5. Relação limbo:haste (L:H), relação vivo:morto (V:M) e altura média do relvado (AMR) dos sistemas com Zeyheria tuberculosa (T1) e controle (T2)

\begin{tabular}{cccc}
\hline Tratamento & $\mathrm{L} / \mathrm{H}$ & $\mathrm{V} / \mathrm{M}$ & AMR $(\mathrm{cm})$ \\
\hline $\mathrm{T} 1$ & $3,2 \mathrm{a}$ & $19,9 \mathrm{a}$ & $64,0 \mathrm{a}$ \\
$\mathrm{T} 2$ & $3,8 \mathrm{a}$ & $9,4 \mathrm{~b}$ & $48,6 \mathrm{~b}$ \\
\hline DMS (Tukey) & 1,2 & 10,4 & 4,7 \\
CV (\%) & 43,5 & 90,7 & 10,7 \\
\hline
\end{tabular}

Valores seguidos por letras distintas na coluna diferem entre si pelo teste Tukey $(\mathrm{P}<0,05)$.

$\mathrm{DMS}=$ diferença mínima significativa pelo teste Tukey $(\mathrm{P}<0,05), \mathrm{CV}=$ coeficiente de variação.

Não foram encontradas diferenças $(\mathrm{P}>0,05)$ quanto ao parâmetro relação limbo:haste. No entanto, foi verificado um estiolamento da planta, AMR, indicando que as plantas sombreadas foram mais altas que aquelas do controle $(\mathrm{P}<0,05)$. Segundo Samarakoon et al. (1990), o cultivo de várias espécies de gramíneas forrageiras sob diferentes níveis de redução da intensidade luminosa resultou em plantas mais altas e com colmos mais longos, o que, segundo Skuterud (1984), seria uma compensação pela redução da luminosidade. 
Quanto aos parâmetros obtidos in vitro (Tab. 6), não foi verificado diferença $(\mathrm{P}>0,05)$ entre as taxas de degradação fracional $(\mu)$ entre dois tratamentos (T1 e T2). O potencial máximo de produção de gases foi mais alto $(\mathrm{P}<0,05)$ para $\mathrm{o}$ T2 (217,2ml) quando comparado ao T1 (202,9ml). Para o tempo de colonização observou-se comportamento inverso, isto é, T2 foi menor que $\mathrm{T} 1$, resultado provavelmente relacionado à maior concentração de FDA, que proporcionou maior tempo de colonização das bactérias sobre os substratos.

Tabela 6. Parâmetros* obtidos por meio da técnica in vitro semi-automática de produção de gases dos sistemas com Zeyheria tuberculosa (T1) e controle (T2)

\begin{tabular}{cccc}
\hline Tratamento & $\mu$ & $\mathrm{A}$ & $\mathrm{T}$ \\
\hline $\mathrm{T} 1$ & $0,0237 \mathrm{a}$ & $202,9 \mathrm{~b}$ & $2,4 \mathrm{a}$ \\
$\mathrm{T} 2$ & $0,0239 \mathrm{a}$ & $217,2 \mathrm{a}$ & $2,1 \mathrm{~b}$ \\
\hline DMS & 0,0013 & 5,3 & 0,2 \\
CV $(\%)$ & 5,5 & 3,2 & 7,3 \\
\hline
\end{tabular}

Valores seguidos por letras distintas na coluna diferem entre si pelo teste Tukey $(\mathrm{P}<0,05)$.

$\mathrm{A}=$ total de gases produzidos $(\mathrm{ml}), \mu=$ taxa de degradação fracional $\left(\mathrm{h}^{-1}\right), \mathrm{T}=$ tempo de colonização (horas).

$\mathrm{DMS}=$ diferença mínima significativa pelo teste Tukey $(\mathrm{P}<0,05) . \mathrm{CV}=$ coeficiente de variação.

* France et al. (1993).

Pela Tab. 7, na qual se apresenta o volume de gases produzidos nos tratamentos $\mathrm{T} 1$ e $\mathrm{T} 2$, verifica-se que até $24 \mathrm{~h}$ de incubação os tratamentos foram equivalentes, não havendo diferenças entre as produções acumuladas de gases. No entanto, a partir de 48h, no T2 ocorreu maior produção de gases. Tais resultados podem indicar que as diferenças entre os tratamentos estão na fração da forrageira mais lentamente degradada, ou seja, nos constituintes da parede celular.

Tabela 7. Produção acumulada de gases (ml) para Brachiaria brizantha cv. Marandu nos sistemas com Zeyheria Tuberculosa (T1) e controle (T2)

\begin{tabular}{ccccccc}
\hline Tratamento & $6 \mathrm{~h}$ & $12 \mathrm{~h}$ & $24 \mathrm{~h}$ & $48 \mathrm{~h}$ & $72 \mathrm{~h}$ & $96 \mathrm{~h}$ \\
\hline T1 & $20,9 \mathrm{a}$ & $50,7 \mathrm{a}$ & $122,8 \mathrm{a}$ & $174,1 \mathrm{~b}$ & $192,5 \mathrm{~b}$ & $209,4 \mathrm{~b}$ \\
T2 & $22,1 \mathrm{a}$ & $53,4 \mathrm{a}$ & $124,3 \mathrm{a}$ & $181,6 \mathrm{a}$ & $201,9 \mathrm{a}$ & $220,4 \mathrm{a}$ \\
\hline DMS (Tukey) & 1,7 & 3,8 & 5,9 & 5,3 & 5,3 & 5,3 \\
CV (\%) & 10,3 & 9,4 & 6,2 & 3,8 & 3,4 & 3,2 \\
\hline
\end{tabular}

Valores seguidos por letras distintas na coluna diferem entre si pelo teste Tukey $(\mathrm{P}<0,05)$.

$\mathrm{DMS}=$ diferença mínima significativa pelo teste Tukey $(\mathrm{P}<0,05), \mathrm{CV}=$ coeficiente de variação.

Na Fig. 2 ilustra-se o volume de gases produzido por hora para cada tratamento. Por ela vê-se que não houve diferenças entre tratamentos quanto à elevação na taxa de fermentação dos carboidratos (CHO) solúveis, porém a elevação na taxa de fermentação dos CHO fibrosos foi maior para o $\mathrm{T} 2$ em relação ao $\mathrm{T} 1$, fato que provavelmente se explica pelo maior teor de FDA na área sombreada.

O sombreamento natural com Z. tuberculosa afetou $(\mathrm{P}<0,05)$ a degradabilidade ruminal in vitro da $\mathrm{MS}$ e da $\mathrm{MO}$, reduzindo em 2,5\% a degradabilidade da forrageira estudada (Tab. 8).
A degradabilidade da B. brizantha cv. Marandu no Ssp com Z. tuberculosa foi mais baixa em relação à da forragem obtida em pleno sol. Este resultado está de acordo com verificações de Wilson et al. (1990) que encontraram dados de digestibilidade in vitro da matéria seca (DIVMS) mais baixos em resposta ao sombreamento. Entretanto, alguns autores não verificaram efeito da intensidade luminosa sobre a digestibilidade (Fleicher et al., 1984), e outros encontraram resultados ainda mais conflitantes, detectando elevação da DIVMS de forrageiras sombreadas (Samarakoon et al., 1990). 


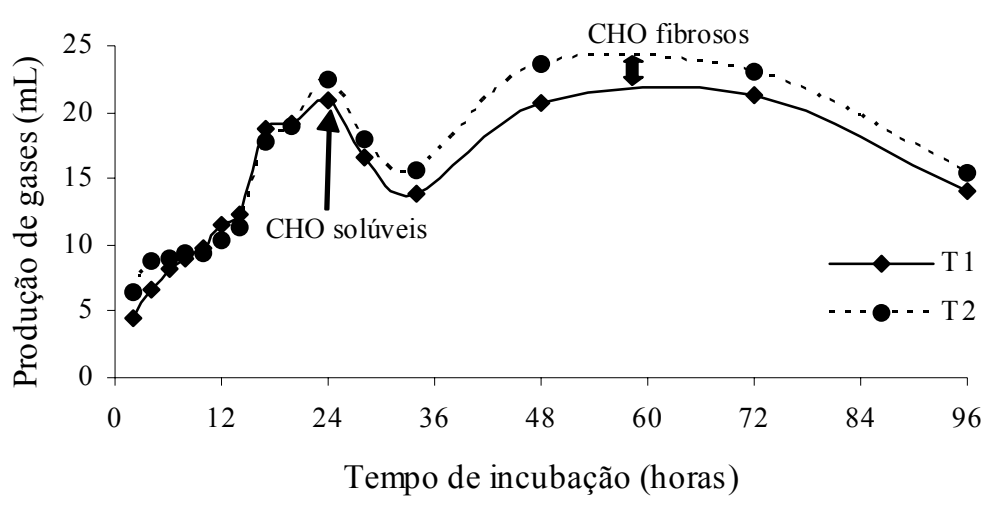

Figura 2. Produção de gases por hora da Brachiaria brizantha cv. Marandu nos sistemas com Zeyheria Tuberculosa (T1) e controle (T2).

Tabela 8. Degrababilidade in vitro (\%) com 96 horas de incubação dos sistemas com Zeyheria tuberculosa (T1) e seu controle (T2)

\begin{tabular}{ccc}
\hline Tratamento & Matéria seca & Matéria orgânica \\
\hline T1 & $65,54 \mathrm{~b}$ & $68,06 \mathrm{~b}$ \\
T2 & $68,06 \mathrm{a}$ & $71,80 \mathrm{a}$ \\
\hline DMS & 1,90 & 2,45 \\
CV $(\%)$ & 3,64 & 4,46 \\
\hline
\end{tabular}

Valores seguidos por letras distintas na coluna diferem entre si pelo teste Tukey $(\mathrm{P}<0,05)$.

$\mathrm{DMS}=$ diferença mínima significativa pelo teste Tukey $(\mathrm{P}<0,05) . \mathrm{CV}=$ coeficiente de variação.

Os dados da Tab. 9 indicam que o sombreamento natural não influenciou a degradabilidade efetiva da $B$. brizantha cv. Marandu. Rodrigues et al. (2004), ao trabalharem com três acessos de $B$. brizantha, encontraram valores de degradabilidade efetiva entre 54,7-61,0\% e 43,0-
$47,7 \%$ para plantas com 21 e 42 dias, respectivamente. Isso indica que os dados obtidos, 41,3 e $42,7 \%$, estão abaixo daqueles descritos pelos autores, o que provavelmente está ligado às diferentes condições edafoclimáticas.

Tabela 9. Degradabilidade efetiva da matéria seca (\%)* da Brachiaria brizantha cv. Marandu nos sistemas com Zeyheria tuberculosa (T1) e controle (T2)

\begin{tabular}{cc}
\hline Tratamento & \\
\hline T1 & $41,28 \mathrm{a}$ \\
T2 & $42,65 \mathrm{a}$ \\
\hline DMS & 1,96 \\
CV $(\%)$ & 5,97 \\
\hline
\end{tabular}

Valores seguidos por letras distintas na coluna diferem entre si pelo teste Tukey $(\mathrm{P}<0,05)$.

$\mathrm{DMS}=$ diferença mínima significativa pelo teste Tukey $(\mathrm{P}<0,05), \mathrm{CV}=$ coeficiente de variação.

$* \mathrm{k}=0,02$.

\section{CONCLUSÕES}

O sombreamento proporcionado pela $Z$. tuberculosa neste Ssp, apesar de reduzir a produção de matéria seca (MS) da B. brizantha cv. Marandu favorece o aumento do teor de proteína bruta sem alterar a produção de $\mathrm{PB} / \mathrm{ha}$, além de não afetar os teores de FDN. Entretanto, os teores de FDA são maiores em resposta ao sombreamento. O sombreamento reduz a degradabilidade in vitro da MS e da matéria orgânica, mas não altera a degradabilidade efetiva. 


\section{REFERÊNCIAS BIBLIOGRÁFICAS}

ANDERSON, G.W.; MODRE, R.W.; JENKINS, P.J. The integration of pasture, livestock and widely-space pine in South West Western Australia. Agrofor. Syst., v.6, p.195-211, 1988.

CARVALHO, M.M.; ALVIM, M.J. XAVIER, F.D. et al Estabelecimento de sistemas silvipastoris: ênfase em áreas montanhosas e solos de baixa fertilidade. Juiz de Fora, MG: Embrapa - CNPGL, 2002. 11p. (Circular Técnica, 68).

CARVALHO, M.M.. Efeito na produtividade e na qualidade da forragem em pastagens. In: CONGRESSO BRASILEIRO DE BIOMETEOROLOGIA, 2., 1998, Goiânia. Anais... Goiânia: Universidade Católica de Goiás, 1998. p. 99-117.

CARVALHO, M.M.; FREITAS, V.P.; ANDRADE, A.C Crescimento inicial de cinco gramíneas tropicais em um subbosque de angico-vermelho (Anadenanthera macrocarpa Benth.). Past. Trop., v.17, p.24-30, 1995.

CARVALHO, M.M.; SILVA, J.L.O.; CAMPOS JÚNIOR, B.A. Produção de matéria seca e composição mineral da forragem de seis gramíneas tropicais estabelecidas em um sub-bosque de angico vermelho. Rev. Bras. Zootec., v.26, p.213-218, 1997 .

CASTRO, C.R.T.; GARCIA, R.; CARVALHO, M.M. et al. Produção forrageira de gramíneas cultivadas sob luminosidade reduzida. Rev. Bras. Zootec., v. 28, p.919-927, 1999.

COMPÊNDIO brasileiro de alimentação animal. São Paulo: SINDIRAÇÕES/ANFAL; Campinas: CBNA/SDR/MA, 1998. 371p.

FERREIRA, A.M.; CARDOSO, R.M. Clima e reprodução da fêmea bovina. Coronel Pacheco: EMBRAPA-CNPGL, 1993. 35p. (Documentos, 54).

FLEICHER, J.E.; MASUDA, Y.; GOTO, I. The effects of light intensity on the productivity ant nutritive value of green panic (Pannicum maximum var. Trichoglume cv. Petrie). $J$. Jpn. Grassl. Sci., v.30, p.191-194, 1984.

FORBES, J.M. Voluntary food intake and diet selection in farm animals. Wallingford: CAB International, 1998. 532p.

FRANCE, J.; DHANOA, M.S.; THEODOROU, M.K. et al. A model to interpret gas accumulation profiles with in vitro degradation of runinant feeds. J. Theor. Biol., v.163, p.99$111,1993$.

FRANK, A.B.; HOFMAN, L. Light quality and stem numbers in coold-season forage grasses. Crop Sci., v.34, p.468-473, 1994

INSTITUTO BRASILEIRO DE GEOGRAFIA E ESTATÍSTICA - IBGE. Disponível em: $<$ http://www.ibge.gov.br/home>. Acessado em: 16 out. 2005.

LEMAIRE, G.; AGNUSDEI, M. Leaf tissue turnover and efficiency of herbage utilization. In: LEMAIRE, G. HODGSON, J.; MORAES, A. et al. (Eds). Grassland ecophysiology and grazing ecology. London: $\mathrm{CAB}$ International, 2000. p.265-288.
LORENZI, H. Árvores brasileiras. São Paulo: Editora Plantarum, 1992.352p.

MACCREE, K.J. Photosynthetically active radiation. In: LANGE, O.L. (Ed). Encyclopedia of plant physiology. New York: Chapman \& Hall, 1981. v.43, p.41-55.

MACEDO, R.L.G.; VENTURIN, N.; FILHO, A.A.T. Princípios de agrossilvicultura como subsídio do manejo sustentável. Inf. Agropecu., v.21, p.93-98, 2000.

MAURÍCIO, R.M.; MOULD, F.; DHANOA, M.S. et al.. A semi-automated in vitro gas production technique for ruminants feedstuff evaluation. Anim. Feed Sci. Technol., v.79, p.321-330, 1999.

NUNES, I.J. Nutrição animal básica. 2.ed. Belo Horizonte: FEP-MVZ, 1998.

OFFICIAL methods of analysis. 13. ed. Washington DC: AOAC, 1980. 1015p.

PEZO, D.; IBRAHIM, M. Sistemas silvopastoriles. Turrialba, Costa Rica: CATIE, Proyecto Agroflorestal CATIE/GTZ, 1998. 258p. (Materiales de enseñanza, 40).

RODRIGUES, A.L.P.; SAMPAIO, I.B.M.; CARNEIRO, J.C. et al. Degradabilidade in situ da matéria seca de forrageiras tropicais obtidas em diferentes épocas de corte. Arq. Bras. Med. Vet. Zootec., v.56, p.658-664, 2004.

SAMARAKOON, S.P.; SHELTON, H.M.; WILSON, J.R. Voluntary feed intake by sheep and the digestibility of the shaded Stenotaphrum secundatum, Axonopus compressus and Pennisetum clandestinum herbage. J. Agric. Sci., v.114, p.143-150, 1990.

SILVA, S.C. Manejo das plantas forrageiras dos gêneros Brachiaria, Cynodon e Setaria. In: PEIXOTO, A.M.; MOURA, J.C.; FARIA, V.P. (Eds). Volumosos para bovinos. 2.ed. Piracicaba: FEALQ, 1995. p.29-57.

SKUTERUD, R. Growth of Elymus repens (L.) Gould and Agrostis gigantea Roth. at different light intensities. Weed Res., v.24, p.51-57, 1984

TOWNSEND, C.R.; MAGALHÃES J.A.; DE LA COSTA, $\mathrm{N}$. et al.. Condições térmicas ambientais sob diferentes sistemas silvipastoris em Presidente Médici - Rondônia. Porto Velho: EMBRAPA-CPAF, 2000, p.4 (Comentário técnico, 188).

VAN SOEST, P. J.; ROBERTSON, J. B.; LEWIS, B. A. Methods for dietary fiber, neutral detergent fiber and no starch polysaccharides in relation to animal nutrition. $J$. Dairy Sci., v.74, p.3583-3597, 1991.

VIANA, V.M.; MAURÍCIO, R.M.; MATTA-MACHADO, $R$. et al. Manejo de la regeneración natural de especies nativas para la formación de sistemas silvopastoriles en zonas de bosques secos del sureste de Brasil. Agrof. Am., v.9, p.48$52,2002$.

WILSON, J.R.; HILL, K.; CAMERON, D.M. et al. The growth of Paspalum notatum under shade of a Eucalyptus grandis plantation canopy or in full sun. Trop. Grassl., v.24, p.24-28, 1990. 